Proceedings of the 50th Hawaii International Conference on System Sciences | 2017

\title{
Task-technology fit aware expectation-confirmation model towards understanding of MOOCs continued usage
}

\author{
Yuanxin Ouyang ${ }^{1}$, Cui Tang ${ }^{1}$, Wenge Rong ${ }^{1}$, Long Zhang ${ }^{1}$, Chuantao Yin ${ }^{2}$, Zhang Xiong ${ }^{1}$ \\ ${ }^{1}$ School of Computer Science and Engineering, Beihang University, Beijing 100191, China \\ ${ }^{2}$ Sino-French Engineer School, Beihang University, Beijing 100191, China \\ \{ oyyx, tangcui.c, w.rong, zhanglong9527, chuantao.yin, xiongz\}@ buaa.edu.cn
}

\begin{abstract}
Massive Open Online Courses (MOOCs) have been playing a pivotal role among the latest e-learning initiative and obtain widespread popularity in many universities. But the low course completion rate and the high midway dropout rate of students have puzzled some researchers and designers of MOOCs. Therefore, it is important to explore the factors affecting students' continuance intention to use MOOCs. This study integrates task-technology fit which can explain how the characteristics of task and technology affect the outcome of technology utilization into expectationconfirmation model to analyze the factors influencing students' keeping using MOOCs and the relationships of constructs in the model, then it will also extend our understandings of continuance intention about MOOCs. We analyze and study 234 respondents, and results reveal that perceived usefulness, satisfaction and task-technology fit are important precedents of the intention to continue using MOOCs. Researchers and designers of MOOCs may obtain further insight in continuance intention about MOOCs.
\end{abstract}

\section{Introduction}

Massive Open Online Courses (MOOCs) are playing an increasing important role in the field of open and distance education [1], holding the potential to open up access to world class teaching and educational resources beyond geographical and social boundaries[63]. Since MOOCs are mostly open and free to all, they have attracted millions of users' enrollment [2], which improve the modern education, disseminate science around the globe [3], and provide new sources of data and opportunities for large-scale experiments [4]. As the emergent popularity of MOOCs threatened the institution of higher education [5][6], thousands of university students have been studying on MOOCs platforms [3], with the majority being from North
America or Europe rather than from developing world regions such as Africa and Asia [64].

Although MOOCs have been lauded and used all over the world, it is a fact that cannot be ignored that the low course completion rate and the high midway dropout rate of students widely exist. As is reported, no more than ten percent of registered students can finish the courses on MOOCs [1][7][8][9]. Completion rate may not the best way to evaluate learning in MOOCs, but it does reflect some of the existing issues.

Since there is high enrollment but low courses completion rate in MOOCs, this paper tries to find out the factors influencing students to continue using MOOCs rather than accept MOOCs. Previous researches have verify the importance of continuance intention [11][12]. Involving this concept in studying students' behavior in the adoption of MOOCs, the true factors of success depends on continued use rather than first-time use [13]. Therefore, it is necessary to investigate students' continuance intention to use MOOCs platform [66][67]. There are many reasons that why students cannot continue using MOOCs, such as a lack of incentive, failure to understand the content and a lack of focus on the discussion forum [59]. Some researches has examined the openness, reputation and enjoyment [2] that influence MOOC completion. The objective of this research is to identify some factors that influence university students to continue using MOOCs.

In academic study, expectation-confirmation model (ECM) is found to be a robust model for continued IT adoption [10][11]. ECM reveals the variables that influence the continuance usage intention of individuals in the area of information technologies [68]. The variables include perceived usefulness, confirmation, satisfaction and continuance intention. In the past years, researchers have successfully employed ECM with diverse factors to explain users' continuance intention in different domains, like web-based service [14], smartphone banking services [15] and e-learning [16]. Nevertheless, it employs only three variables to explain 
behavioral intention, namely satisfaction, confirmation and perceived usefulness, lack of task focus. However, the capability of an information system that support a task can be delivered by the model of task-technology fit (TTF) [17][18][19][20][21].

The model of task-technology fit (TTF) reveals the linkage between information systems and individual performance [20]. The construct of task-technology fit in this model is the central component [18], representing whether or not a technology provides features and support that "fit" the requirements of a task [18][20]. Task means the behaviors that users require to perform to accomplish a goal [72], and technology is the tool to perform tasks [20]. For example, when the teacher arranges a coursework in class, your task is to complete the coursework, and if you want to the complete the coursework, you need some knowledge, and the knowledge is the technology. Past studies have showed the significance of studying the role of TTF in motivating users to continue using information systems [22] and the influences of TTF on learning [23]. Accordingly, we integrate TTF into ECM and try to investigate university students' continuance intention about MOOCs in this research. As the degree to which the technology offered MOOCs help students in performing their coursework or work, TTF has an antecedent of confirmation and has influence on satisfaction and continuance intention, as with perceived usefulness.

The rest of this paper is organized as follows. Section 2 presents the basic theory related to this research, including expectation-confirmation model (ECM) and task-technology fit (TTF). In section 3, we will describe the proposed model. Experimental process as well as results are presented in section 4 . Section 5 and section 6 will describe discussion for the results and conclusion about the research respectively.

\section{Theoretical background}

\subsection{Expectation-confirmation model (ECM)}

Expectation-confirmation model (ECM) was originally presented by Bhattacherjee in 2001 [11]. The model is based on expectation-confirmation theory (ECT) [24], which has been extensively applied to study consumer satisfaction, post-purchase behavior and service marking in general in the consumer behavior literature [25][26][27][28]. ECT has also been used in social psychology, sociology, and public policy domains [29]. Adapted expectation-confirmation theory (ECT) to the information system (IS) continuance context, expectation-confirmation model (ECM) focuses on cognitive beliefs and factors influencing one's intention to continue using information system (IS) [11].
Fig. 1 depicts the constructs and relationships of ECM. Perceived usefulness means the perceptions regarding what the users will gain by using the information system, and the confirmation is the perception of harmony between users' expectation to the IS and the actual using experience of IS [11]. Satisfaction is the emotion of users after using the IS, and the continuance intention is the target of the model, expressing the users' intention to the continuance usage of the information system [11]. Users' extent of confirmation has positive effects on their perceived usefulness of IS. Users may accept the IS though they don't have high initial perceived usefulness to it, then after initial use, they realize their initial perceptions were low and the confirmation experience will elevate users' perceived usefulness [11][30]. Users' perceived usefulness and confirmation are positively associated with their satisfaction with IS, which means if users believe the IS is very useful and better than expectation, they will be more satisfied with the IS. Then due to users' satisfaction and perceived usefulness, they will continue using the IS.

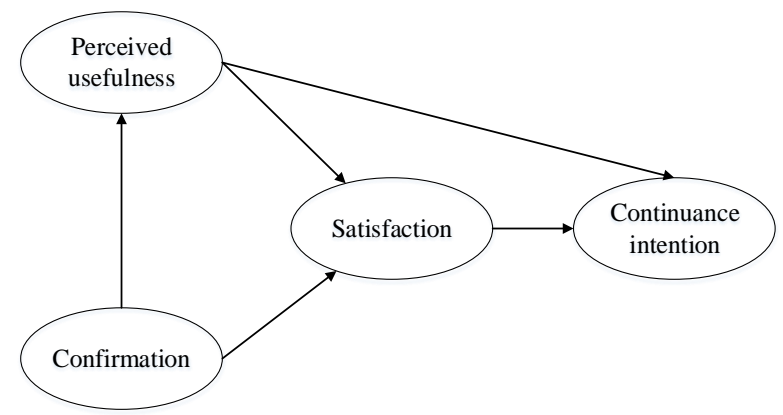

Figure 1. Expectation-confirmation model

ECM and its reformation has been widely applied in various IT products and services. Susanto et al. (2016) used ECM, modified to include perceived security and privacy, trust and self-efficacy to investigate the continuance intention to use the smartphone banking services. The results indicate that the confirmation after the initial use of smartphone banking services significantly influence users' satisfaction, perceived usefulness, trust and perceived security [31]. Stone and Baker-Eveleth (2013) used ECM to study students' intention to continue using electronic textbooks, finding that confirmation influence perceived usefulness and satisfaction with electronic textbooks and satisfaction and perceived usefulness of electronic textbooks affect continuance intention to electronic textbooks [32]. Similarly, Apollos et al. (2016) used an amended ECM to examine continue intention to use mobile instant messaging [33]. In a study of continuance intention to using web service with a variation ECM including intimacy and familiarity, satisfaction was found 
meaningful to continuance intention, and both intimacy and familiarity variables were measured to be important [14].

\subsection{Task-technology fit (TTF)}

Goodhue and Thompson (1995) proposed tasktechnology fit model, revealing the linkage between information systems and individual performance [20]. The basic TTF model is composed of four key constructs: task characteristics, technology characteristics, task-technology fit and utilization [20][35]. Considering the fit between task and technology, tasktechnology fit is the central components of the model [18]. The fit will determine individual's performance, when a technology provides features and support that "fit" the requirements of a task [20][34]. In other words, if you supply better technology to a specified task, and the perception of task-technology fit is great, then user will obtain high individual performance to the given task [18].

Empirical studies posited that a better fit between task and technology will yield the expectation of improved learning outcome [36][37]. McGill et al. used TTF to reveal that "the better the fit of an LMS to the skills of an instructor and the tasks that the instructor must complete, the more positive its effect on their performance is likely to be" [38]. In research [39], TTF are applied in the context of digital video tools use for oral presentation in a classroom environment, and results indicate that there is a significant fit between digital video tools (technologies) and improvement of oral presentation skills(tasks).

In the present study, the construct of tasktechnology fit is thought of the perception of individuals that the technology offered on MOOCS helping students in performing their coursework or work. This perception was tested by the perceived impacts from students' evaluations.

\section{Hypotheses}

In an effort to understand the students' intention to continue using MOOCs, we integrate TTF into expectation-confirmation model (see Fig. 2). TTF is incorporated in the model to reflect the fit of the task and technology students are learning, which is influenced by the extent of confirmation after initial acceptance, and has a positive influence on satisfaction and continuance intention about MOOCs.

Due to ECM is applied as a baseline model, the research measured the ECM hypothesized relationship in the MOOCs. Bhattacherjee indicated that IS usage confirmation is positively associated with satisfaction and perceived usefulness. And empirical results revealed an

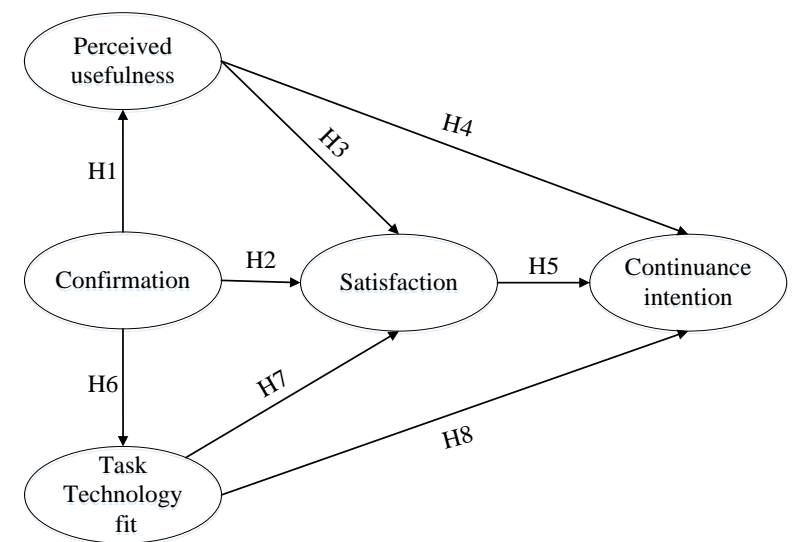

Figure 2. The research model

explicit connection between confirmation and satisfaction [2][24][40] and perceived usefulness [41][42][43]. Previous studies have confirmed that perceived usefulness is a robust and direct determinant of continued IS usage intentions [10][11][44]. There is a positive link between perceived usefulness and user satisfaction in research [10][11][12]. Moreover, satisfaction defined as the "perception of enjoyment and accomplishment in learning environment" in web-based learning, has a strong effect on continuance intentions [44][45][46]. In addition, studies [16][17][47] applied ECM to explain and predict users' continuance intention toward elearning showing the appropriateness of the study. Since MOOC is a kind of e-learning, we derive the following hypotheses from ECM:

H1. Students' extent of confirmation has positive effects on their perceived usefulness of MOOCs.

H2. Students' extent of confirmation has positive effects on their satisfaction with MOOCs.

H3. Students' perceived usefulness has positive effects on their satisfaction with MOOCs.

H4. Students' perceived usefulness has positive effects on their continuance intention about MOOCs.

H5. Students' satisfaction has positive effects on their continuance intention about MOOCs.

Just like the connection between confirmation and usefulness in ECM [11], students may have low initial perceived task-technology fit of a new MOOC, because they are uncertain what they can get from MOOCs and whether it is benefit to their coursework or work. So the low perceived task-technology fit come into being. But after using the MOOC for a period time, students find that their initial low task-technology fit perceptions are unrealistically low, then they will 
improve their perceived task-technology fit owing to the confirmation. To put it another way, confirmation is inclined to raise students' perceived task-technology fit and disconfirmation will depress such perceptions. Therefore, we hypothesize the following:

H6. Students' extent of confirmation has positive effects on their perceived task-technology fit.

Goodhue and Thompson (1995) have already reported the positive relationship between tasktechnology fit (TTF) and utilization [20]. Utilization can be perceived as user adoption [48] or as the behavioral intention to use [19][49]. Researchers have empirically tested the positive link between task-technology fit (TTF) and satisfaction [13]. In this study, this construct is integrated to measure students' satisfaction with the degree to which the knowledge or technology obtained from MOOCs helps their coursework or work. Therefore, we hypothesize the following:

H7. Students' perceived task-technology fit has positive effects on their satisfaction with MOOCs.

It is revealed that task-technology fit (TTF) and satisfaction are significant precedents of the intention to continue using VLS (Virtual Learning System) and individual performance [13]. Researchers have empirically tested that the perceived the ease of use and the degree of usefulness are linked to task-technology fit
[50]. This construct is integrated here to test students' continue intention to use MOOCs whether links with the degree to which the knowledge or technology obtained from MOOCs help their coursework or work. Therefore, we hypothesize the following:

H8. Students' perceived task-technology fit has positive effects on their continuance intention about MOOCs.

\section{Result and Analysis}

\subsection{Data Collection}

The data used to test research model is obtained from questionnaires which are completed by some students in a university of China from August to October in last year. The MOOCs that the students in this university experienced are in two categories, one is that they are mandatory to use it, because they need to satisfy courses' need, the other is that they use it by themselves, because they want to learn some useful knowledge or technologies on it. The questionnaire items were written in English to avoid issues with translation, designed into two parts. The first part is the main body of the questionnaire, consisting of 15 questions to measure the 5 constructs. Every question utilizes a seven-point scales with anchors from "Strongly disagree (1)" to "Strongly agree (7)". The second part

Table 1. Survey items

\begin{tabular}{|c|c|c|c|}
\hline Constructs & Items & Measures & Reference \\
\hline Perceived usefulness(PU) & $\begin{array}{l}\text { PU1 } \\
\text { PU2 } \\
\text { PU3 }\end{array}$ & $\begin{array}{l}\text { Using MOOCs improves my learning performance. } \\
\text { Using MOOCs increases my learning effectiveness. } \\
\text { I find MOOCs is useful for me. }\end{array}$ & Roca et al. [51] \\
\hline Confirmation(CNF) & $\begin{array}{l}\text { CNF1 } \\
\text { CNF2 } \\
\text { CNF3 }\end{array}$ & $\begin{array}{l}\text { My experience with using MOOCs was better than I ex- } \\
\text { pected. } \\
\text { The service level provided by MOOCs was better than I } \\
\text { expected. } \\
\text { Overall, most of my expectations from using MOOCs were } \\
\text { confirmed. }\end{array}$ & $\begin{array}{l}\text { Bhattacherjee } \\
\text { [11] }\end{array}$ \\
\hline Task-technology fit(TTF) & $\begin{array}{l}\text { TTF1 } \\
\text { TTF2 } \\
\text { TTF3 }\end{array}$ & $\begin{array}{l}\text { I think that using MOOCs would be well suited for the way } \\
\text { I like to study tasks. } \\
\text { MOOCs would be a good tool to provide the way I like to } \\
\text { study tasks. } \\
\text { Using MOOCs fit well for the way I like to study tasks. }\end{array}$ & Lee et al. [18] \\
\hline Satisfaction(SAT) & $\begin{array}{l}\text { SAT1 } \\
\text { SAT2 } \\
\text { SAT3 }\end{array}$ & $\begin{array}{l}\text { How do you feel about your overall experience with } \\
\text { MOOCs use? } \\
\text { Very dissatisfied/Very satisfied } \\
\text { Very frustrated/Very contented } \\
\text { Absolutely terrible/Absolutely delighted }\end{array}$ & $\begin{array}{l}\text { Bhattacherjee } \\
\text { [11] }\end{array}$ \\
\hline Continuance intention(CI) & $\begin{array}{l}\text { CI1 } \\
\text { CI2 } \\
\text { CI3 }\end{array}$ & $\begin{array}{l}\text { I will continue using MOOCs in the future. } \\
\text { I will strongly recommend MOOCs for others to use it. } \\
\text { I will keep using MOOCs as regularly as I do now. }\end{array}$ & $\begin{array}{l}\text { Roca et al. [51] } \\
\text { Chiu et al. [45] }\end{array}$ \\
\hline
\end{tabular}


consisting of 4 questions to investigate the background information of the informants, such as gender, age group, MOOCs platforms they used, and the number of courses they have finished. We conducted the survey with financial rewarding to encourage students to complete the questionnaire exploring their use of MOOCs. The questionnaires were distributed in different places at different time in the university. We received a total of 267 responses, and for the sake of the quality of the data, then we discard some responses that fit following criteria: 1) Respondents never or just use MOOCs. 2) Respondents have wrong or paradoxical answers. Finally, there were 234 valid questionnaire responses and it is regarded as an effective data set.

\subsection{Model Measurement}

The reliability of the original data was evaluated by Cronbach's $\alpha$ to measure internal consistency. The mean, standard deviation of each question and Cronbach's $\alpha$ of each construct is shown in Table 2. As listed in Table 2, each of the Cronbach's $\alpha$ is above the recommended value 0.7 [52]. The result indicates that subscales in the survey have a high internal reliability.

Table 2. Question standardization and reliability analysis

\begin{tabular}{|c|c|c|c|}
\hline Construct Code & Mean & SD & Cronbach's $\alpha$ \\
\hline PU1 & 4.64 & 1.393 & \\
PU2 & 4.45 & 1.330 & 0.879 \\
PU3 & 4.73 & 1.457 & \\
\hline CNF1 & 4.38 & 1.306 & \\
CNF2 & 4.39 & 1.189 & 0.829 \\
CNF3 & 4.42 & 1.214 & \\
\hline TTF1 & 4.68 & 1.224 & \\
TTF2 & 4.74 & 1.255 & 0.901 \\
TTF3 & 4.49 & 1.226 & \\
\hline SAT1 & 4.61 & 1.236 & \\
SAT2 & 4.60 & 1.281 & 0.850 \\
SAT3 & 4.60 & 1.424 & \\
\hline CI1 & 4.77 & 1.329 & \\
CI2 & 4.51 & 1.347 & 0.876 \\
CI3 & 4.46 & 1.359 & \\
\hline \multicolumn{3}{|l}{} \\
\hline
\end{tabular}

Bartlett's testing of sphericity and the KaiserMeyer-Olkin (KMO) of Sampling Adequacy were calculated for all measured factors to test the adequacy of data [53] before factor analysis. The results statics of $\chi^{2}(234)=2680.322(\mathrm{p}<0.000)$ and the KMO measure $=$ $0.939(>0.500)$, which supplied the suitability of conducting factor analysis.

The purpose of assessing construct validity of the measurement model is to exam whether the sample data support empirically for the proposed model. And construct validity is divided into convergent validity and discriminant validity. Fornell and Larcker [54] suggested that convergent validity is evidenced when 1) all of the item factor loadings $(\lambda)$ are above 0.5 [17], 2) the composite reliability (CR) of each construct should be greater than 0.7 [2][55], 3) the average variance extracted (AVE) should exceed 0.5 [2][17][55]. As seen in Table 3 , all of the item factor loadings $(\lambda)$, the composite reliability $(\mathrm{CR})$ of each construct and the average variance extracted (AVE) satisfy the recommended threshold values.

Table 3. Model measurement

\begin{tabular}{|c|c|c|c|}
\hline Construct Code & Item loading $(\lambda)$ & CR & AVE \\
\hline PU1 & 0.731 & & \\
PU2 & 0.704 & 0.764 & 0.519 \\
PU3 & 0.725 & & \\
\hline CNF1 & 0.735 & & \\
CNF2 & 0.796 & 0.758 & 0.514 \\
CNF3 & 0.607 & & \\
\hline TTF1 & 0.641 & & \\
TTF2 & 0.795 & 0.750 & 0.502 \\
TTF3 & 0.681 & & \\
\hline SAT1 & 0.556 & & \\
SAT2 & 0.793 & 0.782 & 0.552 \\
SAT3 & 0.847 & & \\
\hline CI1 & 0.647 & & \\
CI2 & 0.797 & 0.797 & 0.569 \\
CI3 & 0.809 & & \\
\hline
\end{tabular}

Discriminant validity was tested comparing the square root of average variance extracted (AVE) for each construct and the correlations between any other constructs [54]. Only when the square root of average variance extracted (AVE) for each construct is bigger than the correlations between any other construct then the constructs in the model meet the discriminant validity [54]. The results are illustrated in Table 4, and values in the diagonal are the square root of AVE, which is greater than the inner-construct correlations.

Table 4. Correlation matrix and discriminant validity

\begin{tabular}{|c|c|c|c|c|c|}
\hline & PU & CNF & TTF & SAT & CI \\
\hline PU & $\mathbf{0 . 7 2 0}$ & & & & \\
\hline CNF & 0.669 & $\mathbf{0 . 7 1 7}$ & & & \\
\hline TTF & 0.699 & 0.689 & $\mathbf{0 . 7 0 9}$ & & \\
\hline SAT & 0.649 & 0.702 & 0.668 & $\mathbf{0 . 7 4 3}$ & \\
\hline CI & 0.691 & 0.675 & 0.702 & 0.679 & $\mathbf{0 . 7 5 6}$ \\
\hline
\end{tabular}

\subsection{Hypotheses tests}

Table 5 illustrates the statistics of the chi-square to degrees of freedom ratio $\left(\chi^{2} / \mathrm{df}\right)$, the normed fit index (NFI), the Non-Normed Fit Index (NNFI), the good- 
ness-of-fit-index (GFI), the comparative fit index (CFI), and the root mean square error of approximation (RMSEA). The results of the indices exceed the recommended value [56][57][58], indicating that the research model provides a good fit to the data. Then it is supported to proceed to path analysis for the proposed model.

Table 5. Overall indices for the research model

\begin{tabular}{|l|c|c|}
\hline & Results & Recommended value \\
\hline$\chi^{2} / \mathrm{df}$ & 2.070 & $<3.0$ \\
\hline NFI & 0.941 & $>0.90$ \\
\hline NNFI & 0.958 & $>0.90$ \\
\hline GFI & 0.920 & $>0.90$ \\
\hline CFI & 0.968 & $>0.90$ \\
\hline RMSEA & 0.068 & $\leq 0.08$ \\
\hline
\end{tabular}

Structural equation modeling (SEM) was employed to test the proposed hypotheses. Fig. 3 and Table 6 depict the eight hypothesized relationships between diverse factors. Note that the results significantly support all hypotheses except the link between tasktechnology fit and satisfaction.

\section{Discussion}

This study posits a conceptual framework integrating task-technology fit (TTF) into expectationconfirmation model (ECM) to analyze the factors that enhance university students' intention to continue using MOOCs. Empirical results provide significant support to the proposed model, indicating ECM can better explain and predict students' continuance intention about MOOCs. Besides, it is also found that tasktechnology fit do influence students' intention to continue using MOOCs systems indeed.

It is not surprising to find the hypotheses in ECM are all supported. Students' extent of confirmation deriving from the performance of MOOCs and initial expectation to the MOOCs is essential determined of perceived usefulness as well as satisfaction with MOOCs. Satisfaction, in turn, will significantly contribute to continuance intention about MOOCs. These findings correspond to previous research [11]. From the results, we also prove the direct influence of perceived usefulness on students' satisfaction and continuance intention about MOOCs. It is obvious that when students believe studying on MOOCs platforms will be useful in improving their capability or helpful for them to find new jobs, they will tend to continue using MOOCs [59]. Therefore, it is important for MOOCs platforms to enhance the quality of courses to improve students' perceived usefulness.

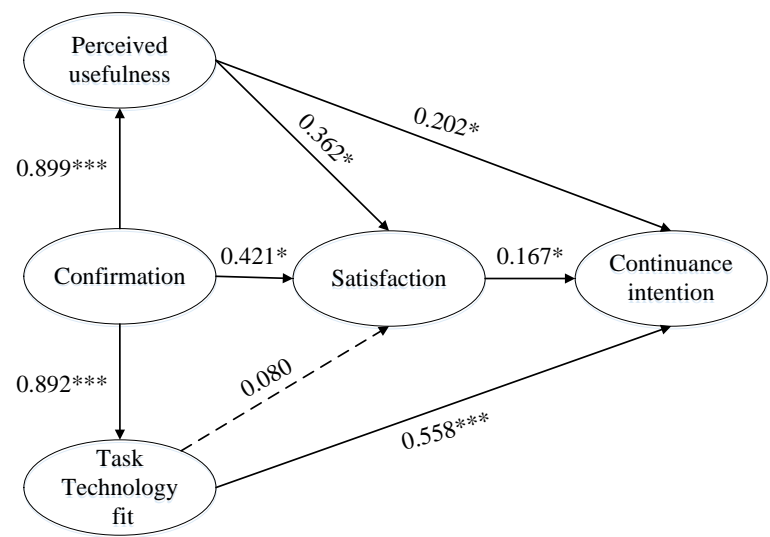

Figure 3. Path Verification

Table 6. Hypotheses test

\begin{tabular}{|l|c|c|}
\hline \multicolumn{1}{|c|}{ Hypothesis } & Estimate & Supported? \\
\hline H1. CNF->PU & $0.899 * * *$ & Y \\
\hline H2. CNF->SAT & $0.421^{*}$ & Y \\
\hline H3. PU->SAT & $0.362^{*}$ & Y \\
\hline H4. PU->CI & $0.202^{*}$ & Y \\
\hline H5. SAT->CI & $0.167 *$ & Y \\
\hline H6. CNF->TTF & $0.892^{*} * *$ & Y \\
\hline H7.TTF->SAT & 0.080 & $\mathrm{~N}$ \\
\hline H8.TTF->CI & $0.558^{*} * *$ & $\mathrm{Y}$ \\
\hline \multicolumn{2}{|c|}{$*: \mathrm{p}<0.1, * *: \mathrm{p}<0.01, * * *: \mathrm{p}<0.001$} \\
\hline
\end{tabular}

It is observed that the strong correlation between confirmation and task-technology fit, suggesting that students' perceived task-technology fit to MOOCs may be adjusted by their extent of confirmation. Further, task-technology fit plays a very important role in analyzing student' continuance intention about MOOCs in this study, which is similar with the study [13]. This result reveals that the fit between knowledge or technology in MOOCs and the task, work or coursework that students are facing with now, can highly influence their intention to continue using MOOCs. Considering that, supplying some courses related to the technology that students are learning in class or be helpful in finding jobs are vital factors in success of MOOCs platforms. Once students recognize they accomplish tasks more quickly, improve their job performance or enhance their job effectiveness [13] assisted by MOOCs, there is a greater tendency to continue using MOOCs.

A significant relationship does not exist between task-technology fit and satisfaction in our study. Satisfaction with web-based learning was defined as the "perception of enjoyment and accomplishment in learning environment" by Sweeney and Ingram [60]. This finding reminds us university students studying on MOOCs may not get much enjoyment and achievability. At the beginning, students have passion to use MOOCs, but with passion consuming, they may feel 
boring and tedious about MOOCs. Nevertheless, students are aware of courses on MOOCs may assist their work or coursework, then they have no choice but to continue using MOOCs despite the perceived dissatisfaction. But it is still significant for MOOCs platforms to be more attractive, since some students may drop out in half way as they cannot stand dull atmosphere and there are low completion rates in MOOCs.

\section{Conclusions, implications, and future work}

Massive Open Online Courses (MOOCs) play an increasing important role in educational area, but the high dropout rate of courses on MOOCs bothers some MOOCs' designers. Researchers have found that there are many factors affecting students' using MOOCs, like hope, enjoyment, effectiveness and instructor interaction in diverse approaches [61][62][65]. This paper integrates task-technology fit into expectationconfirmation model to analyze factors influencing university students to keep using MOOCs. We analyze 234 valid responses and results verify the effect of ECM and TTF on students' intention to keep using MOOCs, especially the fit between task and technology playing a vital role in improving students' continuance intention to the MOOCs.

In the area of information system, the exploration of continuance is very worthwhile and is more vital than the acceptance behavior, which is the one-time behavior [41]. Especially in the field of e-learning, learning is a long process, while patience and persistence are necessary. Therefore, how to attract more loyalty users will be critical to the designers and researchers of MOOCs. ECM is a theoretically rich model in the research of post-acceptance in consumer behavior literature[41], and the extension of ECM in the area of information system, including the research of MOOCs, are also very vital.

This research makes a better understanding of students' continuance intention about MOOCs, providing valuable suggestions or solutions to designers of MOOCs platforms that providing some courses involved the technology that students are learning in class or be beneficial to find jobs may contribute to attract students to keep using MOOCs. The key is to supply some courses or activities that can help university students to do their work or task exactly. Once students find the MOOC is very useful to their career, then they will always choose MOOCs to learn knowledge and technologies, and they will be loyalty to MOOCs. Therefore, perceived usefulness and tasktechnology fit are vital consideration in the design of MOOCs.
Although our study provides some significant contributions, it has some limitations that should be taken into consideration. First, there are a variety of factors that can influence university students to keep using MOOCs, such as perceived openness, perceived reputation, perceived enjoyment and etc., and the research model only takes the fit degree between task and technology into consideration. Thus the model can be integrated into more appropriate factors to discuss the continuance of using MOOCs in future work. On the other hand, the object of study can expand to ordinary people rather than only among university students, and it is believed be more interesting and significant in the future.

\section{Acknowledgements}

This work was partially supported by the National Natural Science Foundation of China (No. 61402028), the Fundamental Research Funds for the Central Universities, and the Fanzhou Education projects of Beihang University.

\section{References}

[1] A. D. Ho, J. Reich, S. O. Nesterko, and et al. HarvardX and MITx: The First Year of Open Online Courses, Fall 2012-Summer 2013, Social Science Electronic Publishing, 2014.

[2] K. M. Alraimi, H. Zo, and A. P. Ciganek, "Understanding the MOOCs continuance: The role of openness and reputation", Computers \& Education, 2015, 80:28-38.

[3] R. A. Rehfeldt, H. L. Jung, A. Aguirre, and et al. "Beginning the Dialogue on the e-Transformation: Behavior Analysis' First Massive Open Online Course (MOOC)", Gait \& Posture, 2016, 9(1):4-13.

[4] J. Reich, "Rebooting MOOC Research", Science, 2015, 347:34-35.

[5] L. Yuan, and S. Powell, "MOOCs and Open Education: Implications for Higher Education", Centre for Educational Technology \& Interoperability Standards, 2013, 4(4):206207.

[6] H. C. Lucas, "Can the Current Model of Higher Education Survive MOOCs and Online Learning”, Educause Review, 2013, 48(5):8.

[7] L. Breslow, D. E. Pritchard, J. Deboer, and et al. "Studying Learning in the Worldwide Classroom Research into edX's First MOOC", Research \& Practice in Assessment, 2013, 8:13-25. 
[8] K. Jordan, "Initial Trends in Enrolment and Completion of Massive Open Online Courses", International Review of Research in Open \& Distance Learning, 2014, 15(15):133160.

[9] S. Kolowich, The professors who make the MOOCs, Chronicle of Higher Education, 2013.

[10] A. Bhattacherjee, "An empirical analysis of the antecedents of electronic commerce service continuance", Decision support systems, 2001, 32(2): 201-214.

[11] A. Bhattacherjee, "Understanding information systems continuance: an expectation-confirmation model", MIS quarterly, 2001: 351-370.

[12] A. Bhattacherjee, J. Perols, and C. Sanford, "Information technology continuance: A theoretic extension and empirical test", Journal of Computer Information Systems, 2008, 49(1): 17-26.

[13] W. S. Lin, "Perceived fit and satisfaction on web learning performance: IS continuance intention and tasktechnology fit perspectives", International Journal of HumanComputer Studies, 2012, 70(7): 498-507.

[14] Y. Lee, and O. Kwon, "Intimacy, familiarity and continuance intention: An extended expectation-confirmation model in web-based services", Electronic Commerce Research and Applications, 2011, 10(3): 342-357.

[15] A. Susanto, Y. Chang, and Y. Ha, "Determinants of continuance intention to use the smartphone banking services: An extension to the expectation-confirmation model", Industrial Management \& Data Systems, 2016, 116(3): 508-525.

[16] C. H. Ho, "Continuance intention of e-learning platform: Toward an integrated model". International Journal of Electronic Business Management, 2010, 8(3): 206.

[17] M. C. Lee, "Explaining and predicting users' continuance intention toward e-learning: An extension of the expectation-confirmation model", Computers \& Education, 2010, 54(2): 506-516.

[18] D. Y. Lee, and M. R. Lehto, "User acceptance of YouTube for procedural learning: An extension of the Technology Acceptance Model", Computers \& Education, 2013, 61: 193-208.

[19] M. T. Dishaw, and D. M. Strong, "Extending the technology acceptance model with task-technology fit constructs", Information \& management, 1999, 36(1): 9-21.

[20] D. L. Goodhue, and R. L. Thompson, "Task-technology fit and individual performance", MIS quarterly, 1995: 213236.
[21] D. M. Strong, M. T. Dishaw, and D. B. Bandy, "Extending task technology fit with computer self-efficacy", ACM SIGMIS Database, 2006, 37(2-3): 96-107.

[22] T. J. Larsen, A. M. Sørebø, and $\varnothing$. Søreb $\varnothing$, "The role of task-technology fit as users' motivation to continue information system use", Computers in Human Behavior, 2009, 25(3): 778-784.

[23] T. J. McGill, and J. E. Klobas, "A task-technology fit view of learning management system impact", Computers \& Education, 2009, 52(2): 496-508.

[24] R. L. Oliver, "A cognitive model of the antecedents and consequences of satisfaction decisions", Journal of marketing research, 1980: 460-469.

[25] E. W. Anderson, and M. W. Sullivan, "The antecedents and consequences of customer satisfaction for firms", Marketing science, 1993, 12(2): 125-143.

[26] J. E. McGrath, and J. R. Kelly, Time and human interaction: Toward a social psychology of time, Guilford Press, 1986.

[27] R. L. Oliver, "Cognitive, affective, and attribute bases of the satisfaction response", Journal of consumer research, 1993: 418-430.

[28] L. E. Sandelancls, and G. C. Buckner, "Of art and work: Aesthetic experience and the psychology of work feelings", Research in organizational behavior, 1989, 100: 105-131.

[29] M. A. Hossain, and M. Quaddus, "Expectationconfirmation theory in information system research: A review and analysis", Information systems theory, Springer New York, 2012: 441-469.

[30] S. Halilovic, and M. Cicic, "Antecedents of information systems user behaviour - extended expectation-confirmation model", Behaviour \& Information Technology, 2013, 32(4):359-370.

[31] A. Susanto, Y. Chang, and Y. Ha, "Determinants of continuance intention to use the smartphone banking services: An extension to the expectation-confirmation model", Industrial Management \& Data Systems, 2016, 116(3): 508-525.

[32] R. W. Stone, and L. Baker-Eveleth, "Students' expectation, confirmation, and continuance intention to use electronic textbooks", Computers in Human Behavior, 2013, 29(3):984-990.

[33] A. P. Oghuma, C. F. Libaque-Saenz, S. F. Wong, and et al. "An expectation-confirmation model of continuance intention to use mobile instant messaging", Telematics and Informatics, 2016, 33(1): 34-47. 
[34] M. Pagani, "Determinants of adoption of high speed data services in the business market: evidence for a combined technology acceptance model with task technology fit model”, Information \& Management, 2006, 43(7): 847-860.

[35] T. C. Lin, and C. C. Huang. "Understanding knowledge management system usage antecedents: An integration of social cognitive theory and task technology fit", Information \& Management, 2008, 45(6): 410-417.

[36] A. D. Carswell, and V. Venkatesh, "Learner outcomes in an asynchronous distance education environment", International Journal of Human-Computer Studies, 2002, 56(5): 475-494.

[37] T. J. McGill, and J. E. Klobas, "A task-technology fit view of learning management system impact", Computers \& Education, 2009, 52(2): 496-508.

[38] T. McGill, J. Klobas, and S. Renzi, "LMS use and instructor performance: The role of task-technology fit", International Journal on E-Learning, 2011, 10(1): 43-62.

[39] A. Raven, E. Leeds, and C. W. Park, "Digital video presentation and student performance: A task technology fit perspective", International Journal of Information and Communication Technology Education (IJICTE), 2010, 6(1): 1729.

[40] R. L. Oliver, and W. S. Desarbo, "Response Determinants in Satisfaction Judgments", Journal of Consumer Research, 1988, 14(4):495-507.

[41] C. S. Lin, S. Wu, and R. J. Tsai, "Integrating perceived playfulness into expectation-confirmation model for web portal context", Information \& management, 2005, 42(5): 683-693.

[42] Q. Min, and X. Shenghua, "An extended expectation confirmation model for information systems continuance", Wireless Communications, Networking and Mobile Computing, 2007: 3879-3882.

[43] S. J. Hong, J. Y. L. Thong, and K. Y. Tam, "Understanding continued information technology usage behavior: A comparison of three models in the context of mobile internet”, Decision support systems, 2006, 42(3): 1819-1834.

[44] K. Y. Lin, and H. P. Lu, "Why people use social networking sites: An empirical study integrating network externalities and motivation theory", Computers in Human Behavior, 2011, 27(3): 1152-1161.

[45] C. M. Chiu, M. H. Hsu, S. Y. Sun, and et al. "Usability, quality, value and e-learning continuance decisions", Computers \& Education, 2005, 45(4): 399-416.
[46] A. Hayashi, C. Chen, T. Ryan, and et al. "The role of social presence and moderating role of computer self efficacy in predicting the continuance usage of e-learning systems", Journal of Information Systems Education, 2004, 15(2): 139.

[47] J. Wu, R. J. Tsai, C. C. Chen, and et al. "An integrative model to predict the continuance use of electronic learning systems: hints for teaching", International Journal on ELearning, 2006, 5(2): 287.

[48] T. Zhou, Y. Lu, and B. Wang, "Integrating TTF and UTAUT to explain mobile banking user adoption", Computers in human behavior, 2010, 26(4): 760-767.

[49] D. C. Yen, C. S. Wu, F. F. Cheng, and et al. "Determinants of users' intention to adopt wireless technology: An empirical study by integrating TTF with TAM", Computers in Human Behavior, 2010, 26(5): 906-915.

[50] H. H. Chang, "Task-technology fit and user acceptance of online auction", International Journal of Human-Computer Studies, 2010, 68(1): 69-89.

[51] J. C. Roca, C. M. Chiu, and F. J. Martínez, "Understanding e-learning continuance intention: An extension of the Technology Acceptance Model", International Journal of human-computer studies, 2006, 64(8): 683-696.

[52] J. C. Nunnally, I. H. Bernstein, and J. M. F. Berge, Psychometric theory, New York: McGraw-Hill, 1967.

[53] J. F. Hair, W. C. Black, B. J. Babin, and et al. Multivariate data analysis, Upper Saddle River, NJ: Pearson Prentice Hall, 2006.

[54] C. Fornell, and D. F. Larcker, "Evaluating structural equation models with unobservable variables and measurement error", Journal of marketing research, 1981: 39-50.

[55] M. K. O. Lee, C. M. K. Cheung, and Z. Chen, "Acceptance of Internet-based learning medium: the role of extrinsic and intrinsic motivation", Information \& management, 2005, 42(8): 1095-1104.

[56] D. Gefen, D. Straub, and M. C. Boudreau, "Structural equation modeling and regression: Guidelines for research practice", Communications of the association for information systems, 2000, 4(1): 7 .

[57] P. M. Bentler, and D. G. Bonett, "Significance tests and goodness of fit in the analysis of covariance structures", Psychological bulletin, 1980, 88(3): 588 .

[58] R. Nargundkar, Marketing Research-Text \& Cases 2E, Tata McGraw-Hill Education, 2003.

[59] K. F. Hew, and W. S. Cheung, "Students' and instructors' use of massive open online courses (MOOCs): Motiva- 
tions and challenges", Educational Research Review, 2014, 12: $45-58$.

[60] J. C. Sweeney, and D. Ingram, "A comparison of traditional and web-based tutorials in marketing education: An exploratory study", Journal of Marketing Education, 2001, 23(1): 55-62.

[61] J. Dillon, G. A. Ambrose, N. Wanigasekara, and et al. "Student affect during learning with a MOOC", Proceedings of the Sixth International Conference on Learning Analytics \& Knowledge, ACM, 2016: 528-529.

[62] G. Veletsianos, and P. Shepherdson, "A Systematic Analysis and Synthesis of the Empirical MOOC Literature Published in 2013-2015", The International Review of Research in Open and Distributed Learning, 2016, 17(2).

[63] K. S. Hone, and G. R. E. Said, "Exploring the factors affecting MOOC retention: A survey study", Computers \& Education, 2016, 98:157-168.

[64] T. R. Liyanagunawardena, A. A. Adams, and S. A. Williams, "MOOCs: A systematic study of the published literature 2008-2012", The International Review of Research in Open and Distributed Learning, 2013, 14(3): 202-227.

[65] P. G. Barba, G. E. Kennedy, and M. D. Ainley, "The role of students' motivation and participation in predicting performance in a MOOC Motivation and participation in MOOCs”, Journal of Computer Assisted Learning, 2016.

[66] J. A. Greene, C. A. Oswald, and J. Pomerantz, "Predictors of retention and achievement in a massive open online course", American Educational Research Journal, 2015: 0002831215584621.

[67] S. I. Freitas, J. Morgan, and D. Gibson, "Will MOOCs transform learning and teaching in higher education? Engagement and course retention in online learning provision", British Journal of Educational Technology, 2015, 46(3): 455471.

[68] G. Dağhan, and B. Akkoyunlu, "Modeling the continuance usage intention of online learning environments", Computers in Human Behavior, 2016, 60: 198-211.

[69] D. M. Eveleth, L. J. Baker-Eveleth, and R. W. Stone, "Potential applicants' expectation-confirmation and intentions", Computers in Human Behavior, 2015, 44(C):183-190.

[70] C. Mingmuang, V. Chongsuphajaisiddhi, and B. Papasratorn, "Factors influencing continuance intention to use PSTN: A pilot study of an extended expectation confirmation model for legacy technology", 2015 Seventh International Conference on Ubiquitous and Future Networks, IEEE, 2015: 874-878.

[71] C. F. Fang, D. G. Lee, and K. S. Han, "A Study on the Effect of Contents Characteristics and Operating Service Quality in Continued Usage Intention and Word of Mouth: Focus on Online Sports Game", Journal of Korea Game Society, 2015, 15(1): 101-114.

[72] R. M. Fuller, and A. R. Dennis, "Does Fit Matter? The Impact of Task-Technology Fit and Appropriation on Team Performance in Repeated Tasks", Information Systems Research, 2009, 20(1):2-17. 